\title{
Perceptions of community members towards youth abusing alcohol in the Capricorn District of the Limpopo Province, South Africa
}

\author{
TM Mothiba, MCur (Health Service Management) \\ Lecturer, Department of Nursing, University of Limpopo, Turfloop Campus \\ RN Malema, MSc (Community Health) \\ Lecturer, Department of Nursing, University of Limpopo, Turfloop Campus
}

\section{Kev words}

Perception; Alcohol abuse; Youth; Community; Behaviour

\section{Abstract: Curationis 32 (4): 48-54}

Alcohol abuse is a problem in South Africa and it has negative effects on the wellbeing of individuals, families, friends, work associates and neighbors. Alcohol produces both psychological and physical dependence. Gillies (1999:112) indicated that alcoholism usually interferes with the ability to socialize, work and may lead to much other destructive behaviour. It was further stated that people who are addicted to alcohol often have a low self-esteem, immaturity, are easily frustrated, and have difficulty in solving personal problems. This study investigated the perceptions of community members towards youth abusing alcohol and identified, among others, anti-social behavior, poor interpersonal relationships, family disorganization, poor integration with family members and physical damage as the major concerns. An attempt was also made to develop strategies that can be used to overcome the problems of alcohol abuse by youth.

Design and Method: A qualitative, exploratory, descriptive and contextual research design was followed in this study for the participants to describe their perceptions regarding the phenomenon in question (Brink, 2006:113). Data were collected through individual unstructured interviews in one village of the Capricorn District of the Limpopo Province. The researchers employed the principles of Guba and Lincoln (1993) cited in De Vos (1998:331) relating to trustworthiness and adhered to the ethical standards as set by the Democratic Nurses Association of South Africa (DENOSA, 1998:2.3.2).

Findings: Five themes and seven categories emerged from the data analysis, using Tech's open coding approach (1990), as outlined in De Vos (1998:343), namely, antisocial behaviour, poor interpersonal behaviour, physical damage, poor progress in life processes and effects of alcohol on the body. To address the problem of alcohol abuse by youth in one village (the study area) of the Capricorn District in the Limpopo Province and other villages the study recommends that educational and recreational facilities and the formation of youth structures should be established.

\section{Correspondence address}

University of Limpopo, Turfloop Campus

mariatm@ul.ac.za 


\section{Introduction and background}

Alcohol abuse is a phenomenon that results in major social, economic and health problems for those individuals afflicted, their families, friends, neighbours, work associates and society. Several factors, including constitutional and environmental, can lead to alcohol abuse (Paton, 1996:5). The consumption of alcoholic beverages in South Africa has a long history and it is outlined that during pre-colonial times, alcohol drinking was mainly preserved for elders, senior members of society and traditional healers, but it was uncommon among youth of childbearing age (Miller, 2001:247). On contrary research in South Africa has shown that, since 1994, more and younger people in rural communities are abusing alcohol, claiming that it is their right to consume alcohol (Smith, 1997:261). The study conducted by Latimer, Rojas and Mancha (2008:325) indicated that alcohol use amongst youth is prevalent worldwide and the researchers reported problematic use in Russia, South Africa, United States and Puerto Rico.

According to Paton (1996:1), alcohol produces both psychological and physical dependence because people who are drunk usually have low selfesteem and are violent - sometimes fatal - tendencies. Alcoholism usually interferes with an individual's ability to reason, socialize, and work which also lead to other forms of destructive behaviour. People who are addicted to alcohol are often immature, become easily frustrated and have difficulty in solving personal problems and in relating to people of the opposite sex. Alcohol abuse affects the youth's well being and social relationship with community members (Smith, 1997:261). The youth of today frequently manifest outward signs of disrespect and interact poorly with community members. The approval or acceptance of alcohol abuse by family members, friends or society as normal may encourage an addicted person to continue unabated. Moreover, it has been reported that children of alcohol abusers are more problematic and disobedient (Baker, 1999: 178).

The recommendations of this study should be included in health education programmes to encourage the youth and community members to realize the damaging effects of alcohol abuse on personal well-being and social relationships.

\section{Problem statement}

Alcohol abuse amongst the youth in one community in the Capricorn District of the Limpopo Province seems to cause problems for example leaving school by youth, teenage pregnancy, physical fights and poor interpersonal relationships between the youth and other community members. These problems, as perceived by community members, arise because the youth are increasingly displaying anti-social behaviour, such as hostility, attacking, fighting and hurting people with knives and other dangerous objects. People who are abusing alcohol escape from reality and have been described as fearful, withdrawn and depressed. Some abusers have a history of frequent suicidal attempts or self-inflicted injuries while others display dependency personalities in that they experience difficulties in taking care of themselves (Smith, 1997:261). The health education program for prevention of alcohol abuse among the youth in schools and health care facilities seem not to be available in the healthcare facilities and community centers.

\section{Purpose of the study}

The purpose of this study was to explore and describe the perceptions of community members towards the youth who abuse alcohol at a village of the Capricorn District in the Limpopo Province of South Africa to develop health education program with guidelines which will assist youth to stop abusing alcohol.

\section{Objectives of the study}

- To explore and describe the perceptions of community members towards youth who abuse alcohol at a village of the Capricorn District in the Limpopo Province of South Africa.

- To develop strategies that could be included in youth health education program regarding the prevention of alcohol abuse amongst the youth.

\section{Research questions}

- What are the perceptions of community members towards youth who abuse alcohol at a village of the Capricorn District in the Limpopo Province of South A frica?

\section{Operational definitions}

\section{Abuse}

Abuse is anything that is harmful, injurious or offensive, and it includes excessive and wrongful misuse of anything (Behrman, 2000:57). In this study, abuse is defined as the misuse and excessive drinking of alcohol which results in addiction and negative interpersonal relationships amongst community members.

\begin{abstract}
Alcohol
Alcohol is defined as a depressant drug that is produced by fermentation of sugar and is the psychoactive constituent intoxicating beverage (Smith, $1997: 251$ ). In this study, alcohol is any liquor or brew containing alcohol as the active agent that people, including youth, consume.
\end{abstract}

\section{Youth}

The United Nations (UN) defines young people as individuals who are female or male aged between 15 and 24 years (O'Higgins, 1997:1). In South Africa, young people are considered to be females or males aged from 14 to 35 years old (National Youth Commission, 1997:5; Kenniston, 1997:5). In this study, youth refers to both females and males from 15 to 25 years of age.

\section{Perception}

Perception is defined as an attitude or understanding based on what is observed or thought (Henry, 2003: on line). In this study, perception means the views of the community members based on their observation and experiences regarding the youth who are abusing alcohol.

\section{Community member}

Community member is defined as a person who lives within the community, interact, react, expect other members to act and interact with him/her within the given geographical area (Bartle, 2007:3). In this study community member is a person who lives within the community and interact with youth who abuse alcohol in a given geo- 
graphical area.

\section{Behaviour}

It is defined as the manner of behaving or conducting oneself (South African Oxford School Dictionary, 2007:40). In this study behaviour means the manner in which youth behave or conduct themselves after alcohol consumption.

\section{Ethical considerations}

Ethical standards, as outlined by DENOSA position statements (1998:2.3.2), were used in this study. All participants signed an informed consent form before they could participate in the study. The purpose of the study was explained to each participant before commencing with the in-depth oneon-one unstructured interview sessions. Permission to conduct the interviews was obtained from the clinic manager of the village's healthcare facility in the Capricorn District of the Limpopo Province. The participants were made aware that they were not forced to answer any questions if they felt the questions violated their rights of confidentiality. The participants were informed that field notes would be written and that a tape recorder would be used during interviews to capture the proceedings of interview sessions and the tapes will be destroyed after two years. Participants were allocated numbers and their real names were not used to ensure confidentiality and anonymity in the entire research project.

\section{Research methodology}

In this study, a qualitative, explorative, descriptive and contextual research design assisted the researcher to obtain complete and accurate information about the perceptions of the community members towards youth who are abusing alcohol in one village of the Capricorn District in the Limpopo Province of the Republic of South Africa (Denzin \& Lincoln, 2000:489). The participants were given an opportunity to describe their perceptions towards youth who are abusing alcohol during one-on-one in-depth unstructured interview sessions. The exploratory design enabled the researcher to ask probing questions from participants to obtain extensive data with regard to the phenomenon under study. The contextual interest by the researcher was aimed at understanding events of the phenomenon studied within the concrete, natural context in which they occur in one village in the Capricorn District of the Limpopo Province (Babbie \& Mouton, 2001:272; Brink, 2006:113).

\section{Research design}

A qualitative phenomenological research method was used for this study, because it was aimed at exploring, describing and promoting understanding of how participants perceived alcohol abuse by youth in their village. The method further allowed the researcher to gain a full view of the study area. The participants were given an opportunity to describe their perceptions regarding the phenomenon under study during one-on-one in-depth unstructured interviews. Qualitative research is contextual because the participants were given a chance to relate their own perceptions towards youth abusing alcohol in their village (Brink, 2006:113; Denzin \& Lincoln, 2000:489). The findings of the research after data analysis reflected the essence of the participant's perception regarding the phenomenon under study (De Vos, Strydom, Fouche \& Delport, 2006:271).

\section{Inclusion criteria}

The following inclusion criteria determined who participated in the study: The participants were members of the community who attended or accompanied patients at the village's health care facility in the Capricorn district of the Limpopo Province of South Africa. Participants were community members who were able to understand instructions and be able to communicate. Participants gave informed consent before they were included in the study.

\section{Study population}

A study population is the entire group of participants who are of interest to the research in order to meet the criteria that the researcher set (Brink, 1999:121).

The accessible study population comprised of community members who attended or accompanied patients to a healthcare facility in one village of Capricorn District in the Limpopo Province of the Republic of South Africa.

\section{Sampling}

A non-probability purposive sampling method was used in this study. Purposive sampling entails judgmental sampling that involves the conscious selection by the researcher of certain participants or elements to be included in the study (Burns \& Grove, 2005: 475). In this study a community members who attended or accompanied patients to a health care facility in the Capricom District of the Limpopo Province of South Africa were selected. A total number of twenty (20) participants were interviewed over a period of four weeks till data saturation was reached.

\section{Data collection}

Unstructured one-on-one in-depth interviews were conducted during the research study. The purpose of this interview method was to understand the perceptions of the participants as they were given an opportunity to describe their experiences with regard to youth abusing alcohol. Different data collecting methods (triangulation) were used in this study to complement each other in order to maximize the trustworthiness of collected data and to reduce the chance of bias by the researcher (Babbie \& Mouton, 2001:274). The methods included:

- Unstructured one-on-one in-depth interviews.

- Field notes of unstructured one-on-one in-depth interview sessions were recorded verbatim.

The central question was asked to all participants the same was during the interview sessions followed by probing questions because the researcher wanted to understand more about the perception of the community members towards youth who are abusing alcohol. The central question was "Describe how you perceive youth abusing alcohol in this village?"

\section{Data analysis}

The Tesch's open coding approach of data analysis (1990) as outlined in De Vos (1998:343) was used: All tape recordings were listened to and transcribed verbatim. Field notes taken during unstructured in-depth one-onone interviews sessions were given meaning. The ideas that came out of the unstructured in-depth one-on-one 
interview sessions were consolidated. A list of all probing questions and their responses were drawn up and similar topics that emanated from the responses were grouped in columns. The topics were arranged into five themes and four categories. The lists of all topics were compared with the original data. Codes were allocated to data according to identified topics. Data belonging to each category were grouped and analyzed and then final remarks on the data analysis written (De Vos, 1998:345). Raw data were forwarded to an independent coder with no categories. The independent coder then allocated the codes from the original raw data given by the researcher. Thereafter, a meeting was scheduled to discuss and to reach consensus on the categories reached independently (Brink, 2006:185). The literature control was presented after data were collected and analyzed as it formed a basis for comparing and contrasting the findings of the qualitative nature of this study (Creswell, 1994:23).

\section{Trustworthiness}

Trustworthiness was maintained throughout this study by using Guba's model (Babbie \& Mouton, 2001: 276; De Vos et al, 2006:346), concentrating on the following criteria:

\section{Credibility}

Credibility was ensured through prolonged engagement in the health care facility of a village in the Capricorn District of the Limpopo Province until data saturation was reached. Participants who were interviewed were purposively selected and satisfied the research study inclusion criteria (De Vos et al, 2006:346).

\section{Transferability}

The thick description of research methodology was outlined in this study and the research context was explained (Babbie \& Mouton, 2001: 276). The participants were given an opportunity to describe their perceptions towards the youth who abuse alcohol (University of Johannesburg Postgraduate Research Reader for Health Sciences, 2007:166). The study findings are not generalized to all villages in the Capricorn District in the Limpopo Province, but are limited to one village only (De Vos et al, 2006:346). Triangulation of data collection methods were used in the verification of the truth of data collected from the participants themselves and not from the researchers.

\section{Confirmability}

The findings of this research are the products of the research inquiry and not from the researcher's bias. In this study, conformability was ensured by the involvement of the independent coder. Raw data were forwarded to an independent coder with no categories. The independent coder then allocated the codes from the original raw data given by the researcher. Thereafter, a meeting was scheduled to discuss and to reach consensus on the categories reached independently (De Vos, 1998:351; Babbie \& Mouton, 2001:278; Brink, 2006:185).

\section{Limitations of the study}

The study was limited to one village in the Capricorn District of the Limpopo Province and thus the findings of the study are not generalisable to all the villages in the Limpopo Province.

\section{Discussion of the results}

A total number of twenty participants were interviewed over a period of four weeks. Participants were community members who attended or accompanied patients to one village's health care facility in the Capricorn district of the Limpopo Province of South Africa. Table 1 indicates themes and categories emerged from data analysis regarding the phenomenon under study.

\section{Theme 1: Anti-Social Behaviour}

Participants indicated that the youth who abuse alcohol fight with each other and other community members which result to injuries or death. One participant reported that "When people are drunk they start fighting with everything they have, for example, knives and broken bottles". Hannigan, Spear and Norman (1999:34) supported this statement noting that drinking patterns are a common form of abuse in humans, and that they appear to produce more injuries. Participants perceived alcohol abuse by youth as one of the contributing factors to rape incidents in their community. Another respondent stated that: "When young people are drunk, they rape others in- cluding their parents". According to Graves (2000:35), alcohol reduces self control and increases aggressiveness which may result in the alcohol abuser being abusive, raping women and displaying violent behaviour. Neubeck and Neubeck (1997:605) found that half of all murders and a third of all suicides involve drinking, and many people die annually in the United States. It was further stated that physical assaults, child abuse, rape and other sex crimes are thought to be associated with alcohol use.

\section{Theme 2: Poor Interpersonal Behaviour}

\section{Category 2.1: Family Disorganization}

Some of the participants perceived alcohol abuse as one of the causes of family disorganization and eventually family breakups. They stated that " $A l$ cohol brings problems in the families and divorce is one of the results". This statement agrees with reports that divorce was common amongst young alcohol abusers (Buttler \& Hope, 1997:326), and that disruption of family life due to alcohol often end up costing the taxpayer money because there will be unhappy families who will need professional counseling, broken homes which will need repairs, and displaced or deprived children who will need governmental assistance (Neubeck and Neubeck, 1997:601).

\section{Category 2.2: Poor Interaction with Family Members}

Participants indicated that youth who are abusing alcohol develop poor interpersonal interactions with others, including their families. They stated that "When young people are drunk they become arrogant and insult others, including their parents". Miller (2001:134) supports this notion and reports that young people are at high risk of alcohol abuse that predisposes them to poor interpersonal relationships with their family members. Neubeck and Neubeck (1997:601) asserted that the impact of alcoholism often dramatically affects the alcoholic's relationships with other people, especially family members.

\section{Theme 3: Physical Damage}

The results indicated that when young people are drunk, they sustain physical injuries through burns or falls. 


\begin{tabular}{|l|l|}
\hline THEMES & CATEGORIES \\
\hline 1. Anti-Social Behaviour & \\
\hline 2. Poor Interpersonal Behaviour & $\begin{array}{l}2.1 \text { Family Disorganisation } \\
2.2 \text { Poor interaction with family members }\end{array}$ \\
\hline 3. Physical damage & \\
\hline 4. Poor Progress in life processes & $\begin{array}{l}4.1 \text { Unemployment and poverty } \\
\text { 4.2 Poor education progress } \\
4.3 \text { School dropout }\end{array}$ \\
\hline 5. Effects of alcohol on the body & $\begin{array}{l}\text { 5.1 Physiological effects } \\
\end{array}$ \\
\hline
\end{tabular}

Thus another participant stated: "Due to drunkenness, I burned myself when I was trying to cook". This statement is supported by Grief and Golden (1994:116) that alcohol abuse demonstrated increased incidence of people who burn themselves accidentally when they are under the influence of alcohol. Some participants stated that: "Many young people when drunk sustain injuries due to falls". Hannigan, Spear and Norman (1999:34) also supports this statement by observation that drinking patterns are a common form of abuse in humans, and they appear to produce more injuries.

\section{Theme 4: Poor Progress in Life Processes}

\section{Category 4.1: Unemployment and}

Poverty

Participants perceive that youth who abuse alcohol do not seem to have good future. They reported that: "Young people who are drinking do not have a bright future". Butler and Hope (1997: 322) support this notion by affirming that even if you are drinking less than the recommended maximum, your pattern of drinking may be potentially dangerous because it may lead to serious problems in future such as loss of a job, followed by poverty. By contrast, Neubeck and Neubeck (1997:596) observed that the highest percentages of people who do not abuse alcohol are those with only elementary school background, whilst most college graduates are alcohol abusers.

\section{Category 4.2: Poor Educational Progress}

Participants indicated that youth abusing alcohol show poor educational progress. They stated that: "Youth spend most of their time abusing alcohol and not going to school as they were supposed to thus resulting in poor educational progress". Neubeck and Neubeck (1997:596) noted that youth who abuse alcohol are more likely to experience academic problems such as poor class attendance and inability to focus, and thus earn lower grades.

\section{Category 4.3: School dropout}

The study results revealed that youth who abuse alcohol dropout from school and start engaging in negative activities such as fights. One participant reported that "MMM! You know we see miracles in this village youth, always dropout from school and stay in taverns the whole day and night abusing alcohol. During they stay in the tavern you know a lot of things happens they always fight, stab each other with knifes and always engage in unprotected sex, it is really horrible our children do not have future". Brown (1993:665) indicated that there is a high dropout rate from schools amongst African-American youth who are abusing alcohol in the United States of America.

\section{Theme 5: Effects of alcohol on the body}

The study revealed two categories un- der theme 5 which is Physiological effects and Physical effects of alcohol on the body.

\section{Category 5.1: Physiological Effects}

Participants explained that it is not good for the youth to abuse alcohol because it also results in brain damage. They stated that: "Alcohol distorts brain functioning". Graves (2000:8) supports the notion that alcohol may destroy the brain and liver cells and, over time, excessive alcohol consumption may be fatal.

\section{Category 5.2: Physical Effects}

The participants indicated that youth who are abusing alcohol looks older than their age with wrinkles on their faces, skin seem to be worn-out and they walk like older people. One participant stated that "You know madam youth in our place they look like their grandfathers sometimes I will say their grannies are better, their skin are not well nourished they look as is they are old I must tell you and they are always sick". Brown (1993: 667) pointed out that heavy alcohol consumption results in the excess morbidity experienced by blacks compared with whites.

\section{Recommendations}

The following strategies can be used to overcome the problem of alcohol abuse by the youth.

\section{Educational Program}

- The youth must be educated about the after effects of alco- 
hol abuse, such as poor educational progress, and unemployment and violence, so that they may be able to understand the importance of stopping alcohol consumption and addiction (Howe, 2001:44).

- $\quad$ The youth need to be educated about alternative ways of reducing alcohol consumption, such as academic and recreational activities (sports, book clubs) and attending church services. (Howe, 2001:45).

- Education must also be provided to the families to refrain from the practice of sending their children to buy alcohol for them. This will avoid early exposure of youth to alcohol (Gullotta and Adams, 1999183).

- The school curriculum should include strategies to initiate, strengthen and implement norms, values and standards against alcohol and substance abuse (Gordon, 1999:217).

- The families must be encouraged to socialize the youth into accepting the acceptable rules, norms and values of the community and society (Gullotta and Adams, 1999192).

- Health education programmess in churches must be initiated and implemented about the abuse of alcohol by the youth (Gordon, 1999:218).

\section{Recreational Facilities}

- $\quad$ The youth must be encouraged to participate in community projects which will keep them busy and stop them from drinking alcohol (Parry, 1998:175). Youth should be involved in youth recreational activities for example sports, poetry, drama and educating one another as peers about positive aspects of life.

- $\quad$ Support groups must be initiated in rehabilitation centers where most young people will be encouraged and assisted to stop drinking, and to express their feelings about drinking (Parry, 1998:173). Youth should be engaged in group discussions and brainstorm possibili- ties that can assist them to stop abusing alcohol.

\section{Educational Facilities}

- Mobile and community libraries should be provided in the community.

- Expansion of community resources such as community coalitions to prevent alcohol and substance use (Rhodes \& Leonard, 1998:45).

\section{Youth Structures}

- The youth must be given information about the availability of government youth structures such as the Umsobomvu Youth Fund, that can assist them to start their own businesses, especially those who are unemployed (Gullotta \& Adams, 1999:183).

\section{Community Leaders}

- Community leaders such as a chief in the community need to be encouraged to implement the rules that force bottle store owners in the community not to sell alcohol to the youth (Gordon, 1999:217).

- $\quad$ The chiefs must encourage the formation of community police forums to trace people who are selling alcohol without a license.

\section{Rehabilitation Centers}

- Community members must be informed about the availability of alcohol rehabilitation centers that can be utilized by the youth (Parry, 1998:173-175).

\section{Conclusion}

The findings of this study revealed that there are problems associated with youth who abuse alcohol such as family disorganization, poor interaction with family members, unemployment and poverty, poor education progress, school dropout, physiological effects and lastly psychological aspects. The preventive programs could be implemented to assist youth to stop abusing alcohol. The recommendations of the study indicated strategies that can be included in the preventive program for youth who abuse alcohol.

\section{References}

BABBIE, E \& MOUTON, J 2001: The Social Practice of Social Research. Cape Town: Oxford University Press.

BAKER, R 1999: Social Work Dictionary. $4^{\text {th }}$ edition. Washington D.C: Naswa Press.

BARTLE, P 2007: What is community, ASociological Perspective. Lourdes Sadu: Spain

BEHRMAN, RE 2000: Nelson Textbook of Pediatrics. $16^{\text {th }}$ edition. Washington: W.B Saunders Company.

BRINK, HI 2006: Fundamentals of Research Methodology for Health Care Professionals. $2^{\text {nd }}$ Edition. Cape Town: Juta \& Company.

BROWN, LS 1993: Alcohol abuse prevention in African-American communities. Journal of the National Medical Association Vol. 85(9) 665-673

BURNS, N \& GROVE, KS 2005: Practice of Nursing Research. $5^{\text {th }}$ Edition. University of Texas: Arlington.

BUTTLER, G \& HOPE, T 1997: Mental Fitness Guide. Oxford University Press: Oxford.

CRESWELL, JW 1994: Research Design: Qualitative and Quantitative Approaches. Thousand Oaks, London New Delhi: Sage Publishers.

DEMOCRATIC NURSES ORGANIZATION OF SOUTH AFRICA (DENOSA) 1998: Ethical Standards for Nurse Researchers. Pretoria: DENOSA.

DENZIN, NK \& LINCON, YS 2000: Handbook of Qualitative Research. $2^{\text {nd }}$ edition. Thousand Oaks: Sage Publications.

DE VOS, AS 1998: Research at Grass Roots. $1^{\text {s }}$ Edition. Pretoria: Van Schaik.

DE VOS, AS; STRYDOM, H; FOUCHE, CB \& DELPORT, CSL. 2006. Research at Grass roots for the Social Sciences and Human Service Professions. $3^{\text {rd }}$ Edition. Pretoria: JL Van 
GILLIES, H 1999: Counseling young people: A practical guide for parents, teachers, and those in helping professions. Cape Town: Lyn Publications.

GORDON, JU 1999: Managing Multiculturalism in Substance Abuse Services. USA: Sage Publications.

GRAVES, B 2000: Alcohol Use and Abuse: Perspective on Physical Health. USA: Campstone Press.

GRIEF, J \& GOLDEN, BA 1994: Alcoholic Care at Home: A Guide for Care Givers Loved Ones and People with Substance Abuse. USA: Wiley-Liss, Inc.

GULLOTTA, TP \& ADAMS, GR 1999: Substance Abuse in Adolescence. USA: Sage Publications.

HANNIGAN, HJ; SPEAR, LP \& NORMAN, E 1999: Alcohol and Alcohol Effects on Brain and Development. New York: Lawrence Erlbaum Associates.

HOWE, B 2001: Alcohol Education. New York: Routledge Company.

LATIMER, WW; ROJAS, VC \& MANCHA, BE. Severity of alcohol use and problem behaviours among school-based youths in Puerto Rico. Rev Panam Salud Publica Vol. 23(5) 325 332

MILLER, D 2001: Stigma and Substance Abuse in Africa: Setting the Operation Research Agenda. $1^{\text {st }}$ edition. USA: Academic Press.

NEUBECK, KJ; NEUBECK, MA, 1997: Social problems: A critical approach. $4^{\text {th }}$ Edition. New York: McGraw-Hill Companies, Inc.

PARRY, DH 1998: Alcohol Policy and Public Health in South Africa. Cape Town: Oxford University Press.

PATON, A, 1996: ABC of Alcohol. London: BMJ Publishing Group.

RHODES, JE \& LEONARD, AJ 1998: Preventing Substance Abuse Among Children and Adolescence. USA: Pergaman Books, Inc.

SMITH, P 1997: Research
Mindedness for Practice: An Interactive Approach for Nursing Health Care. Oxford: Science Ltd.

SOUTH AFRICAN OXFORD SCHOOL DICTIONARY 2007. Oxford University Press Southern Africa. Cape Town.

UNIVERSITY OF JOHANNESBURG 2007. Postgraduate Research Reader for Health Sciences Reader. Johannesburg: Content Solutions 